\title{
STUDY ON STRENGTHENING BY REHABILITATION OF CRACKED RC SLABS USING DIFFERENT FRP SHEETS UNDER IMPACT LOADING
}

\author{
H N Jagannatha Reddy ${ }^{1}$, Meghana A Patankar ${ }^{2}$ \\ ${ }^{I}$ Professor, Civil Engineering Department, Bangalore Institute of Technology, Bengaluru, Karnataka, India \\ ${ }^{2}$ Assistant Professor, Civil Engineering Department, New horizon college of Engineering, Bengaluru, Karnataka, \\ India
}

\begin{abstract}
Today in the civil engineering industry, majority of buildings are designed to resist the impact and blast load due to increased terror attack. Existing concrete structures designed without consideration of impact load can be vulnerable. This Structure cannot be demolished and re constructed again since it is uneconomical. Hence the best way is to rehabilitate the structure which is damaged. In this study 10 slabs of size $600 \mathrm{~mm} \times 600 \mathrm{~mm} \times 60 \mathrm{~mm}$ of grade M20 were cast. Two slabs were cast as control specimen and were subjected to impact loading till its failure. Remaining slabs were subjected to impact loading up to its first crack and were rehabilitated by wrapping with different FRP sheets. The performance of rehabilitated RCC slabs under impact loading was studied in comparison with the control slabs and the increase in Impact resistance was determined.
\end{abstract}

Keywords:- Rehabilitation, Wrapping Fibers, Impact Loading

\section{INTRODUCTION}

Throughout the early history, Civil Engineering Technologies are growing according to demands and desires of the public. During the process of design various loads are considered like gravitational loads, earthquake loads, seismic loads, wind loads, blast loads, and impact loads. If such buildings are subjected to heavy impact load like rock fall or missile impact load then such buildings will undergo damage. Design of impact resistant structure is an increasing preoccupation in the design of reinforced concrete (RC) structures. With the goal of reducing the damage to structure, many experimental and numerical studies on RC structures have been carried out to understand its behaviour under impact loading. An impact force is a high force or shock applied over the body for very short duration. This impact force has large effect than a lower force applied over a proportionally longer period.

Existing concrete structures designed without consideration of impact load can be vulnerable under impact load. This structure cannot be demolished and reconstructed again since it is uneconomical. Hence, the best way is to rehabilitate the structure which is damaged. Such damaged structures are strengthened by wrapping it by Carbon Fiber Reinforced Polymer [CFRP], Glass Fiber Reinforced Polymer [GFRP], Aramid Fiber Reinforced Polymer [AFRP] and Basalt Fiber Reinforced Polymer [BFRP] sheets which improves the impact resistance of the structure. This study investigates the behavior of RCC rehabilitated slabs subjected to impact loading.

Ten slabs of size $600 \mathrm{~mm} \times 600 \mathrm{~mm} \times 60 \mathrm{~mm}$ of grade M20 were cast. Two slabs were cast as control specimen and were subjected to impact loading till its failure. Remaining slabs were subjected to impact loading up to its first crack and were rehabilitated by wrapping with different FRP sheets. The behavior of rehabilitated RCC slabs under impact loading was studied in comparison with the control slabs. The increase in impact resistance was determined.

\section{OBJECTIVE}

Ongoing through the literature, it was found that many works were carried out on the study of impact force on different kinds of concrete slabs, the study of rehabilitated slabs under impact loading was very limited. Out of those works carried, only certain fabric materials were used for rehabilitation process. Thus in my study all available artificial fiber reinforced polymer fabrics was used as wrapping material for rehabilitation and its performance was studied and compared with each other and with control slab. The main objectives were as follows.

- To determine the number of blows at the time of first crack and at the time of failure.

- To determine energy absorption capacity of control and rehabilitated slabs.

- To determine the increase in the energy absorption capacity of rehabilitated slabs compared with control slabs.

- To know the effective wrapping using different FRP 
to enhance the impact strength.

- To suggest suitable recommendations to the practicing engineers.

\section{MASTER DATA}

\begin{tabular}{|c|c|}
\hline Plan dimension of the slab & $600 \mathrm{~mm} \times 600 \mathrm{~mm} \times 60 \mathrm{~mm}$ \\
\hline Weight of the hammer & $10.2 \mathrm{~kg}$ \\
\hline Height of fall & $1000 \mathrm{~mm}$ \\
\hline Grade of concrete & M20 \\
\hline
\end{tabular}

\section{MATERIALS USED}

The performance of concrete depends on the properties of constituent materials used in the preparation. So, every material used in the experiment should undergo the preliminary tests and should satisfy the necessary requirements as per the standards. In our study, Rehabilitation is done by using wrapping different types of fabrics. Properties of these fabrics also play a major role in strengthening. Thus this highlights the properties of materials used in the experimental program

\subsection{Ordinary Portland Cement}

The tests on OPC was carried out in accordance with IS 4031-1993. The results were tabulated

Table 1: Test on cement

\begin{tabular}{|c|c|c|c|}
\hline Sl.No & Test Conducted & Results & $\begin{array}{l}\text { Codal } \\
\text { provisions }\end{array}$ \\
\hline 1. & $\begin{array}{l}\text { Brand of cement } \\
\text { used }\end{array}$ & $\mathrm{ACC}$ & \\
\hline 2. & Type of cement & $\begin{array}{l}53 \text { grade } \\
\text { OPC }\end{array}$ & \\
\hline 3. & $\begin{array}{l}\text { Specific gravity } \\
\text { of cement }\end{array}$ & 3.15 & \\
\hline 4. & Consistency & $29.2 \%$ & $\begin{array}{l}\text { Around } \\
30 \%\end{array}$ \\
\hline 5. & $\begin{array}{l}\text { Initial setting } \\
\text { time }\end{array}$ & 115 minutes & $\begin{array}{l}\text { Not less } \\
\text { than } 30 \\
\text { minutes }\end{array}$ \\
\hline 6. & Final setting time & 310 minutes & $\begin{array}{l}\text { Not more } \\
\text { than } 600 \\
\text { minutes }\end{array}$ \\
\hline \multirow[t]{4}{*}{7.} & $\begin{array}{l}\text { Compressive } \\
\text { strength }\end{array}$ & & \\
\hline & 3 days & $410 \mathrm{Mpa}$ & $\begin{array}{l}\text { Not less } \\
\text { than } 53.0 \\
\text { Mpa }\end{array}$ \\
\hline & 7 days & $52.0 \mathrm{Mpa}$ & $\begin{array}{l}\text { Not less } \\
\text { than } 53.0 \\
\text { Mpa }\end{array}$ \\
\hline & 28 days & $64.5 \mathrm{Mpa}$ & $\begin{array}{l}\text { Not less } \\
\text { than } 53.0 \\
\text { Mpa }\end{array}$ \\
\hline
\end{tabular}

\subsection{Fine Aggregate}

The particles retained on $4.75 \mathrm{~mm}$ sieve is termed as fine aggregates. The sand used in the study is manufactured sand also called Robo sand. The sample used for casting of slabs satisfies the requirements of grading of Zone II as per IS -383-1970 with specific gravity 2.6

\subsection{Coarse Aggregate}

In the present study we have used $12.5 \mathrm{~mm}$ down size aggregates. The coarse aggregate used in the experimental program were tested according to the standards. Results are given as below.

A] Specific gravity of coarse aggregate $=\mathbf{2 . 6 9}$

B] Aggregate crushing test $\mathbf{2 2 2 . 4 \%}$

C] Aggregate impact test $=\mathbf{2 7 . 0 8 \%}$

Hence the coarse aggregate is of good quality and can be used for construction purpose.

\subsection{Chemical Admixture}

Chemical admixture are typically used in liquid form and in relatively small amounts compared to the other ingredients used in concrete.

Admixtures are used to improve the properties of concrete, an admixture can reduce the total in place cost of concrete construction by shortening the construction cycle and extending the service life of the concrete.

CONPLAST SP 430 is the chemical admixture used for the study.

\subsection{Water}

The water used for mixing of cement, fine aggregates, coarse aggregates and chemical admixture should be pure and fit for drinking. Water should be free from suspended and organic materials. The water should be colourless, odourless and tasteless. Chlorides and sulphates should not be present in water as their presence may cause corrosion of reinforcing bars.

\subsection{Carbon Fibre Reinforced Polymer (CFRP)}

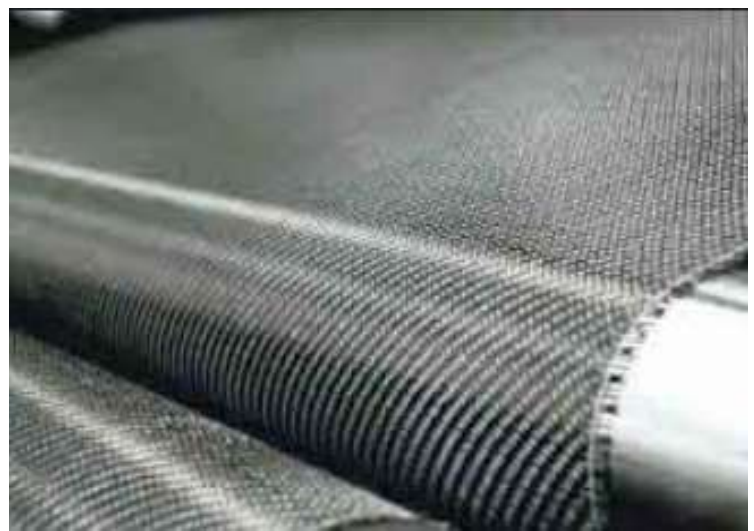

Fig 1: Carbon Fibre Reinforced Polymer 
CFRP is a fabric which is mainly made of Carbon fibres. It can be unidirectional, bidirectional or random. In the present study, unidirectional CFRP of thickness 200 GSM was used. CFRP fabric is very costly and is used in the places where high strength to weight ratio and rigidity are required. The properties of CFRP are given in the table.

Table 2: Properties of CFRP

\begin{tabular}{|l|l|}
\hline PROPERTIES & CFRP \\
\hline Tensile strength & $1720-4900 \mathrm{~N} / \mathrm{mm}^{2}$ \\
\hline Elastic modulus & $120000-580000 \mathrm{~N} / \mathrm{mm}^{2}$ \\
\hline Ultimate tensile strain & $0.5-2.1$ \\
\hline Tensile modulus & $285 \times 10^{3} \mathrm{~N} / \mathrm{mm}^{2}$ \\
\hline Density & 1.8 \\
\hline Fibre orientation & Unidirectional \\
\hline Weight of fibre & $200 \mathrm{~g} / \mathrm{m}^{2}$ \\
\hline
\end{tabular}

\subsection{Glass Fiber Reinforced Polymer (GFRP)}

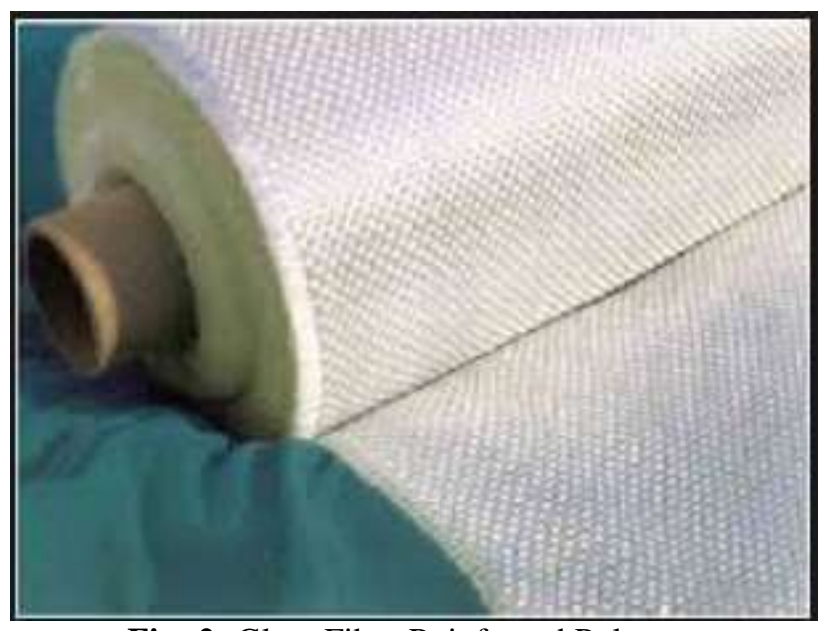

Fig: 2: Glass Fibre Reinforced Polymer

GFRP is a fabric which is mainly made up of glass fiber. The glass fiber may be randomly oriented, may be unidirectional or bidirectional. In the present study, bidirectional GFRP of thickness $900 \mathrm{gsm}$ was used. GFRP is light in weight and strong. The properties are given in table

Table 3: Properties of GFRP

\begin{tabular}{|l|l|}
\hline PROPERTIES & GFRP \\
\hline Tensile strength & $480-1600 \mathrm{~N} / \mathrm{mm}^{2}$ \\
\hline Elastic modulus & $35000-51000 \mathrm{~N} / \mathrm{mm}^{2}$ \\
\hline Ultimate tensile strain & 1.5 \\
\hline Tensile modulus & $73 \times 10^{3} \mathrm{~N} / \mathrm{mm}^{2}$ \\
\hline Density & 1.8 \\
\hline
\end{tabular}

\section{Basalt Fiber Reinforced Polymer (BFRP)}

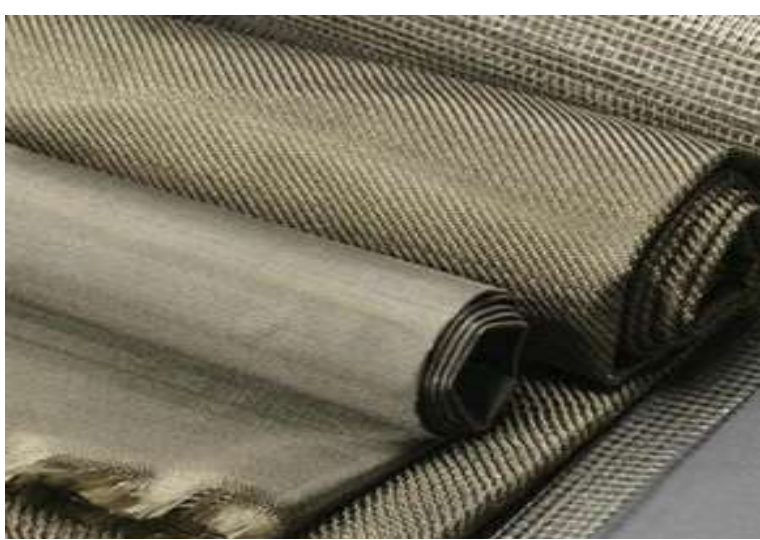

Fig 3: Basalt Fiber Reinforced Polymer

Basalt fiber are made from fine fibers of basalt. It has better physical and mechanical properties than fiberglass. It is cheaper than carbon fiber. BFRP used in this study, was bidirectional with thickness $200 \mathrm{gsm}$. It has high tensile strength and exhibits excellent resistance to acid and alkali, along with the non-magnetic and non-conductive characteristics. Basalt is also non-combustible and offers good thermal protection making it suitable for many insulation and high temperature applications. Now -a- days, BFRP is economical and is used extensively for strengthening purpose because of its high temperature and abrasion resistance. The properties are given below.

Table 4: Properties of BFRP

\begin{tabular}{|l|l|}
\hline PROPERTIES & BFRP \\
\hline Tensile strength & $1300-2500 \mathrm{~N} / \mathrm{mm}^{2}$ \\
\hline Elastic Modulus & $50000-110000 \mathrm{~N} / \mathrm{mm}^{2}$ \\
\hline Ultimate Tensile strain & 3.15 \\
\hline Tensile Modulus & $73 \times 10^{3} \mathrm{~N} / \mathrm{mm}^{2}$ \\
\hline Density & 2.65 \\
\hline
\end{tabular}

\subsection{Aramid Fiber Reinforced Polymer (AFRP)}

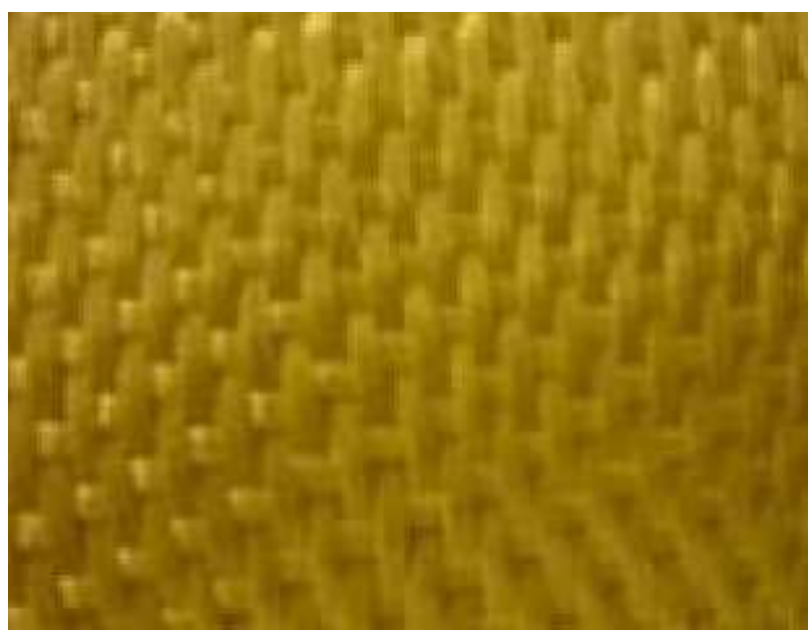

Fig 4: Aramid Fiber Reinforced Polymer 
AFRP is a fabric made of strong synthetic aramid fibres. The word aramid has arrived from two words "aromatic" and "polyamide". $85 \%$ is of amide linkages (-CONH-) attached directly to two aromatic rings, in our study Bidirectional aramid fabric is made use of. It has high heat resistance property. It is light weight fabric, hence it is used where weight reduction is necessary .Its properties are given in table.

Table 5: Properties of BFRP

\begin{tabular}{|l|l|}
\hline PROPERTIES & AFRP \\
\hline Tensile strength & $2600-3600 \mathrm{~N} / \mathrm{mm}^{2}$ \\
\hline Elastic Modulus & $124000-150000 \mathrm{~N} / \mathrm{mm}^{2}$ \\
\hline Ultimate Tensile strain & 3.6 \\
\hline Tensile Modulus & $83 \times 10^{3} \mathrm{~N} / \mathrm{mm}^{2}$ \\
\hline Density & 1.44 \\
\hline
\end{tabular}

\subsection{Epoxy for Wrapping}

For wrapping the polymer fabrics to the slabs adhesives are required .The properties are listed below as per the information given by the suppliers in the table.

Table 6: Properties of Epoxy Nitowrap 410 Saturant

\begin{tabular}{|l|l|}
\hline Colour & Pale yellow to Amber \\
\hline Application temperature & $15 \mathrm{c}^{\circ}-40^{\circ} \mathrm{c}$ \\
\hline Viscocity & Thixotropic \\
\hline Pot life & $2 \mathrm{hr} @ 30^{\circ} \mathrm{c}$ \\
\hline Density & $1.25-1.26 \mathrm{~g} / \mathrm{cc}$ \\
\hline Cure time & 5 days $@ 30^{\circ} \mathrm{c}$ \\
\hline
\end{tabular}

Nitowrap 30, Primer

\begin{tabular}{|l|l|}
\hline Pot life & $25 \mathrm{~min} @ 27^{\circ} \mathrm{c}$ \\
\hline Density & $1.14 \mathrm{~g} / \mathrm{cc}$ \\
\hline Cure time & 7 days \\
\hline
\end{tabular}

\section{EXPERIMENTAL WORK}

AND

\section{METHODOLOGY}

A Well designed equipment set up is essential to study the behavior of rehabilitated RCC slabs under impact loading.

\subsection{Test Specimens}

Ten slab specimens of dimension $600 \mathrm{~mm}$ x $600 \mathrm{~mm}$ x 60 $\mathrm{mm}$ were cast with reinforcement of $6 \mathrm{~mm}$ diameter bars of Fe $500 @ 95$ mm c/c spacing on both sides. Preparation of form work, bar bending, casting of slabs was done.

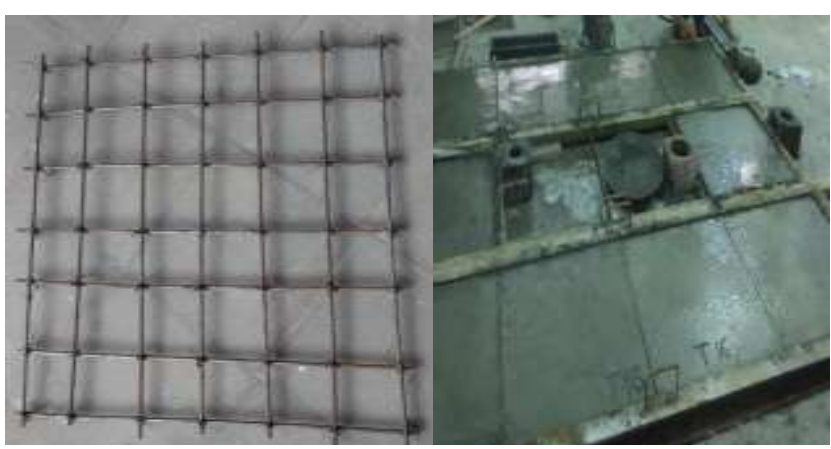

Fig 5: Reinforcement details and slab casting

\subsection{Test Setup}

A typical Test apparatus is shown in Fig. It consists of a steel frame, supported by steel columns on both sides. A steel hammer of weight $10.2 \mathrm{Kg}$ was used as impact on the test specimen. The height of free fall was taken as 1 meter. Centre mark was made on the top surface of the test specimen and placed on the test set up. Clamping was done on all sides to prevent the lifting of slabs during the Impact blows. Pulley arrangement was made to give the impact blows on test specimens.

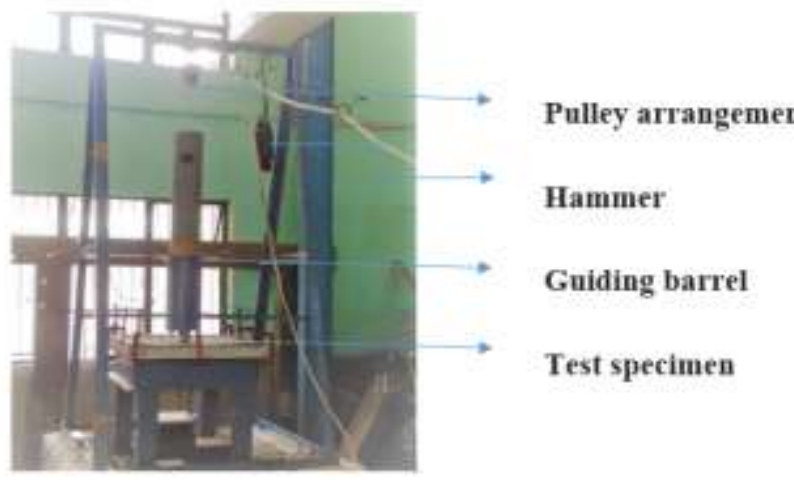

Fig 6: Impact testing apparatus

\subsection{Test Methodology}

Ten slabs were cast, out of which two were taken as control. Centre mark was made on the control slabs and placed on the test set up. Clamping was done on all four sides to prevent lifting of slabs during the impact blows. Impact blows from height of 1 meter was given by pulley arrangement till the appearance of ultimate failure. Number of blows taken by the slabs at the time of first crack and at ultimate failure was noted. Crack pattern was studied. Remaining 8 test specimens were subjected to impact loading till the appearance of first visible crack. Further, these damaged slabs were strengthened (rehabilitated) by wrapping it with different fabrics. Two of the each slabs were strengthened with CFRP, GFRP, BFRP and AFRP respectively

\subsection{Wrapping Technique}

Concrete surface to be strengthened must be free from oil residue, dust, dirt and protrusions. It must be cleaned by 
sand papers. Primer contains two materials i.e. the base and the hardener. In the present study, Nitowrap 30 epoxy primer was used. Before using, thorough shaking of the container is done for uniform suspension. Base and hardener were added to the container in the ration $2: 1$ and it was mixed mechanically for 3 minutes before applying to cleaned surface. Slabs were allowed to dry for next 24 hours before saturant was applied.

This contains base and hardener. In this study Nitowrap 410 saturant is used. Both base and hardener were added to the container in the standard ratio and mixed for 3 minutes. This was applied on the primer. Thickness of the saturant layer was 230 microns. Required size of the fabric was cut and was placed on the saturant layer which was pre applied with gloved hands. To remove the air bubbles after placing the fabric, surface should be pressed gently using spatula and then roller is rolled over the surface. The surface should be pressed with stiff spatula to remove air bubbles. After 30 minutes, one more layer of saturant was applied. The wrapped slabs were left 7 days for curing. The cured strengthened (rehabilitated) RCC slabs was again subjected to impact load and number of blows taken by slabs wrapped with different fabrics was determined. The increase in number of blows, energy absorption, and impact resistance was determined with reference to the control slabs.

\section{RESULTS AND DISCUSSIONS}

The control slabs and rehabilitated slabs were subjected to Impact loading and the response was studied. The number of blows taken by control slabs and rehabilitated slabs at the appearance of first crack and at ultimate failure was noted and compared. Energy absorption capacity of both kinds of slabs was calculated. The increase in energy absorption capacity and Impact resistance of rehabilitated slabs in comparison with the control slabs was determined. Results from these studies are discussed below.

\subsection{Test on Control Slabs}

A very sharp sound was observed for first impact blow which gradually decreased for further blows. This indicated the appearance of first crack. On further impact blows widening of cracks occurred at the bottom surface. With continued impact blows caused deformation of reinforcing bars and spalling of concrete. This stage was considered as the final ultimate failure. Test results are tabulated in Table .The failure pattern of the control slabs is shown below.

Table 7: No. of blows at first crack.

\begin{tabular}{|l|l|l|}
\hline $\begin{array}{l}\text { Specimen } \\
\text { No. }\end{array}$ & $\begin{array}{l}\text { No. of blows at } \\
\text { first crack }\end{array}$ & $\begin{array}{l}\text { No. of blows at } \\
\text { ultimate } \\
\text { failure(N) }\end{array}$ \\
\hline 1 & 4 & 15 \\
\hline 2 & 3 & 14 \\
\hline
\end{tabular}

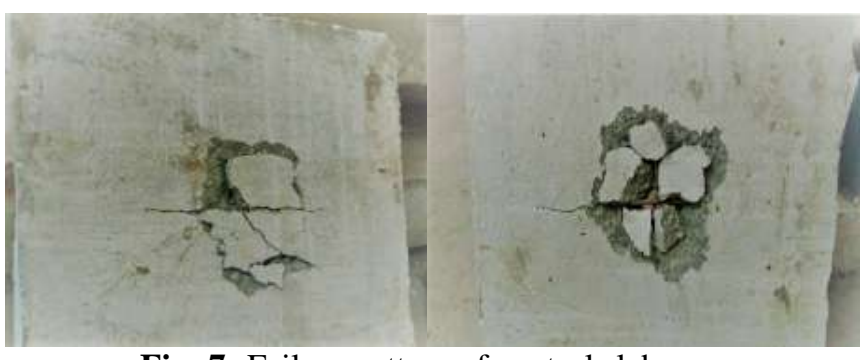

Fig: 7: Failure pattern of control slabs

- Energy absorption capacity of control slabs The energy absorption of the control slabs can be calculated using the formula:

\section{$E=\mathbf{N} \times(\mathbf{w} \times \mathbf{h})$ joules}

Where,

- $\quad$ E is the Energy absorbed in joules,

- $w$ is weight of hammer in Newton,

- $\quad h$ is the height of drop in meter and

- $\mathrm{N}$ is the no. of impact blows.

Here $\mathrm{N}=15, \mathrm{~h}=1 \mathrm{~m}, \mathrm{w}=10.2 \mathrm{~kg}$

Energy absorption of control slabs $=10.2 \times 9.81 \times 1 \times$ 15

$$
=1500 \mathrm{~J}
$$

- Initial impact loading on test specimen

The first crack generally appeared for third or fourth blow .Crack appeared at the center portion of the slab as shown in the figure below. The cracks emerged at the center and radiated outwards. The cracks at the central region were clearly visible when compared to the cracks at the outer region of the slab. The cracks radiated in the outer region disappeared after some time of the testing. This indicated that it was still in the elastic zone.

Table 8: Slabs subjected to impact load up to first crack

\begin{tabular}{|l|l|}
\hline Test specimen & No. of blow at first crack \\
\hline 1 & 4 \\
\hline 2 & 3 \\
\hline 3 & 3 \\
\hline 4 & 4 \\
\hline 5 & 3 \\
\hline 6 & 4 \\
\hline 7 & 4 \\
\hline 8 & 4 \\
\hline
\end{tabular}

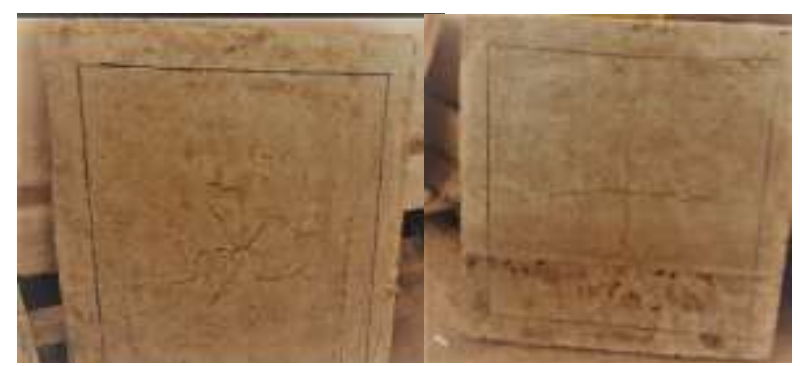

Fig 8: Appearance of First crack. 


\subsection{Test on Rehabilitated Slabs}

The rehabilitated slabs were placed on test apparatus. Clamping of test specimen was done to avoid lifting of slab during the test. Guiding barrel was placed through which Impact blows were given .Since the rehabilitated slabs were already subjected to impact blows until the appearance of first crack, the sound due to first blow on strengthened slabs was not very sharp as the control slab. As the rehabilitated slab was in verge of failure, there appeared a dull sound from the slab to the Impact blows given. FRP sheet wrapped at the bottom started bulging and for further more blows caused peeling or tearing of the sheet. This was considered as the ultimate failure stage.

Table 9: No. of blows at ultimate failure for rehabilitated

\begin{tabular}{|l|l|l|l|}
\hline $\begin{array}{l}\text { Material } \\
\text { used for } \\
\text { wrapping }\end{array}$ & $\begin{array}{l}\text { Trial 1 } \\
\text { No. } \\
\text { blows af } \\
\text { ultimate } \\
\text { failure }\end{array}$ & $\begin{array}{l}\text { Trial 2 } \\
\text { No. } \\
\text { blows of } \\
\text { ultimate } \\
\text { failure }\end{array}$ & Remarks \\
\hline CFRP & 22 & 22 & $\begin{array}{l}\text { TEARING } \\
\text { OF FRP }\end{array}$ \\
\hline GFRP & 20 & 19 & $\begin{array}{l}\text { BULGING } \\
\text { OF FRP }\end{array}$ \\
\hline AFRP & 26 & 26 & $\begin{array}{l}\text { BULGING } \\
\text { OF FRP }\end{array}$ \\
\hline BFRP & 24 & 24 & $\begin{array}{l}\text { BULGING } \\
\text { OF FRP }\end{array}$ \\
\hline
\end{tabular}

The Results obtained after the experimental studies were tabulated and put in the graphical form for easy understanding.

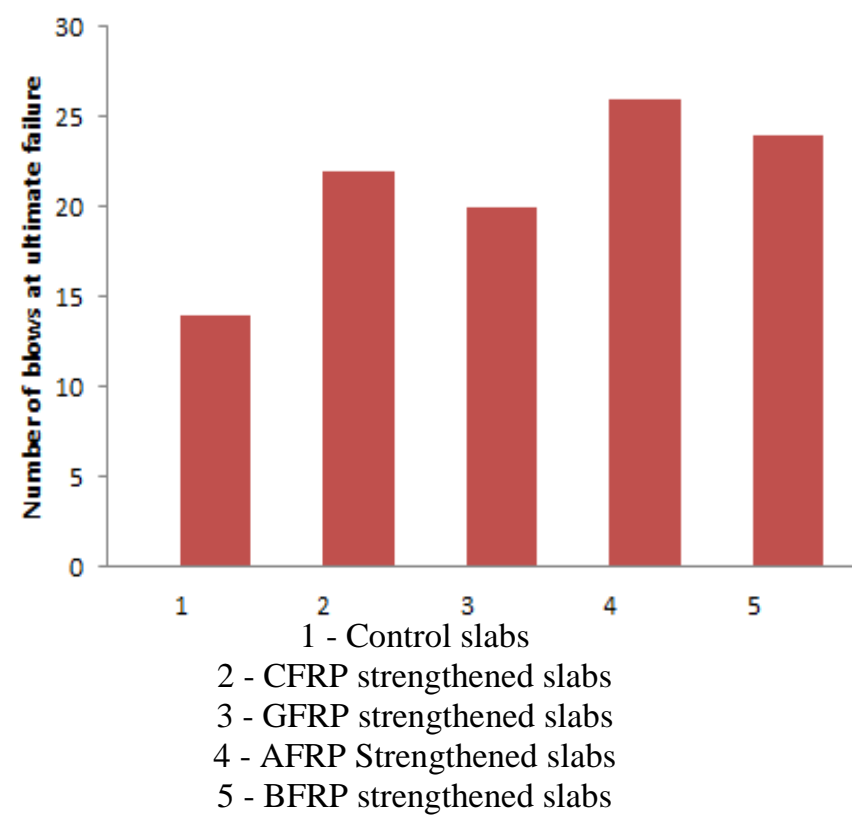

From the figure, observation was made that the AFRP strengthened slabs took more number of blows compared to other slabs

\section{Energy Absorption of the Rehabilitated slabs}

Energy absorption capacity of slabs strengthened with different wrapping materials is as shown in the below table.

Table 8: Energy absorption of control and for rehabilitated

\begin{tabular}{|l|l|l|l|}
\hline $\begin{array}{l}\text { Wrapping } \\
\text { material }\end{array}$ & $\begin{array}{l}\text { Energy } \\
\text { absorption } \\
\text { of control } \\
\text { slab(J) }\end{array}$ & $\begin{array}{l}\text { Energy } \\
\text { absorption of } \\
\text { Rehabilitated } \\
\text { slab(J) }\end{array}$ & $\begin{array}{l}\text { \% increase } \\
\text { in the } \\
\text { Energy } \\
\text { absorption } \\
(\boldsymbol{\%})\end{array}$ \\
\hline \multirow{2nnn}{*}{ CFRP } & \multirow{2}{*}{1500} & 2201.364 & 46.75 \\
\cline { 1 - 1 } GFRP & 1901.178 & 26.74 \\
\cline { 4 - 5 } AFRP & 2601.612 & 73.44 \\
\cline { 4 - 5 } BFRP & 2401.488 & 60.09 \\
\hline
\end{tabular}

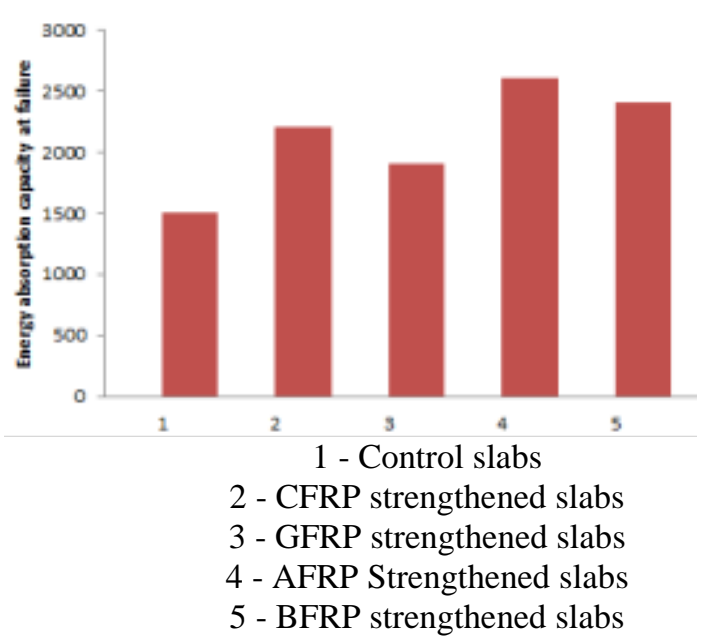

Graph 2: Variation of Energy absorption capacity at failure for control and rehabilitated slabs

From the figure it is observed that AFRP strengthened slab absorbed more energy and showed greater increase in impact resistance than other slabs. The least increase in the impact resistance was shown by GFRP strengthened slabs.

\subsection{Discussion}

\subsubsection{Behavior of CFRP Strengthened Slabs under Impact Loading}

Two damaged slabs were strengthened by wrapping it with unidirectional Carbon fiber reinforced polymer fabric of 200 GSM Thickness. These strengthened slabs were subjected to Impact blows. The CFRP rehabilitated slabs offered good Resistance to the impact blows compared to the control slabs as seen in the above graph. There was emergence of 
sharp sound for the first few blows, which gradually reduced for increased blows. At this stage bulging of CFRP was seen .There was a noticeable sound difference between the portion which was bulged and flat portion when tapped on the surface. Further increase in the Impact blows caused the CFRP sheet to tear. Since the CFRP sheet was unidirectional, tearing of the fabric occurred. The energy absorption capacity of CFRP rehabilitated slabs was 2201.364 J. There was $46.75 \%$ increase in the Energy Absorption capacity of rehabilitated slabs compared to control slabs.

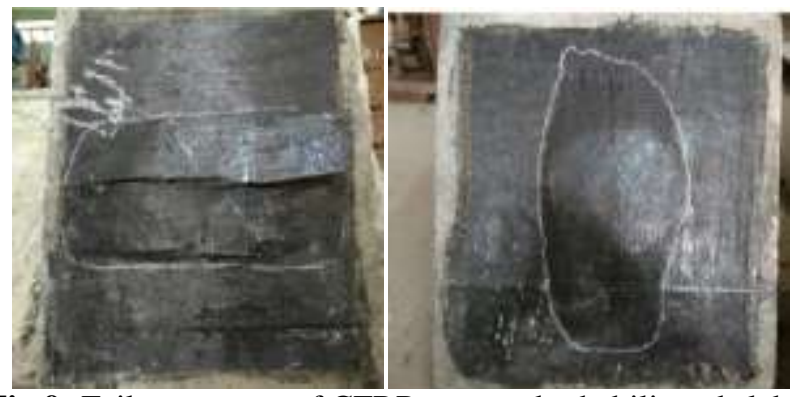

Fig 9: Failure pattern of CFRP wrapped rehabilitated slab.

\subsubsection{Behavior of GFRP Strengthened Slabs under}

\section{Impact Loading}

Other two slabs were strengthened by wrapping with bidirectional glass fiber reinforced polymer fabric of 900gsm thickness. The GFRP strengthened slabs showed increased resistance to impact blows compared to control slabs .After certain Impact blows GFRP at the bottom started bulging. On further increase in the blows, expansion in the bulging area was observed. Since GFRP used was bidirectional, tearing of the fabric was not seen as in case of GFRP. Furthermore blows on the rehabilitated slabs caused peeling or de-bonding of the fabric. This was considered as the ultimate failure. The failure pattern is as shown in the figure below. Analysis of damaged pattern showed that GFRP strengthened slabs has largest damage area than other fabrics. There was just $26.74 \%$ increase in the Energy absorption capacity of rehabilitated slabs compared to control slabs.

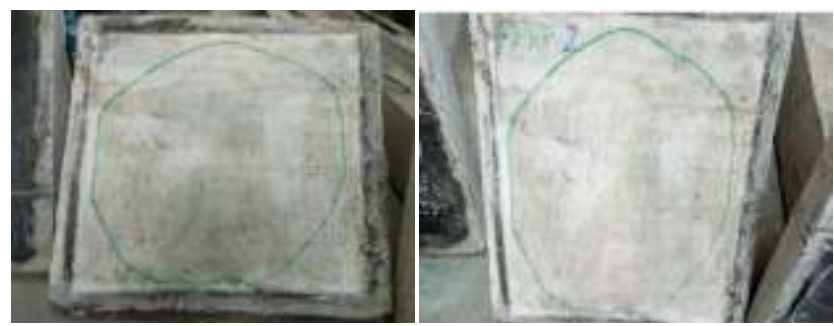

Fig 10: Failure pattern of GFRP wrapped rehabilitated slab

\subsubsection{Behavior of AFRP Strengthened Slabs under}

\section{Impact Loading}

Other two slabs were strengthened by wrapping with Aramid fiber Reinforced Polymer. Aramid fiber used in the study was $200 \mathrm{gsm}$ and bidirectional. There was considerable increase in the energy absorption capacity compared to control slabs. Behavior of bidirectional AFRP fabric was very much better than unidirectional fabric. The response of AFRP was comparatively better than CFRP, GFRP and BFRP. Increase in the impact blows neither caused tearing of the fabric nor, peeling. There was just initiation of bulging and the bulged area expanded as the number of blow increased. The area of bulging was least compared to other fabrics since the aramid fiber absorbed and dispersed the impact energy that is transmitted from the blows very efficiently. This was considered as the ultimate failure point. The failure pattern is as shown in the picture below. There was $73.44 \%$ enhancement in the energy absorptionncapacityu of rehabilitated slabs compared to control slabs.

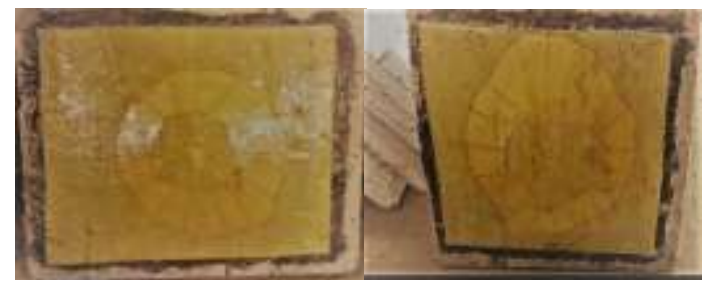

Fig 11: Failure pattern of AFRP wrapped rehabilitated slab. 6.3.4 Behavior of BFRP Strengthened Slabs under

\section{Impact Loading}

Remaining two slabs were strengthened with Basalt fiber reinforced polymer. BFRP used was Bidirectional with 200 gsm as thickness. BFRP wrapped slabs showed improved impact resistance compared to the control slabs. There was emergence of sharp sound for the first few blows, then as Impact blow increased, the sharp sound started fading indicating the failure of the slab. At the bottom initiation of bulging was seen. The bulging area expanded for further more blows. Since BFRP was also bidirectional there was no tearing or peeling of fabric. The behavior of the BFRP wrapped slab was better than slabs wrapped by GFRP and unidirectional CFRP. The failure pattern is as shown in the figure.. There was $60.09 \%$ enhancement in the energy absorption capacity $\mathrm{u}$ of rehabilitated slabs compared to control slabs.

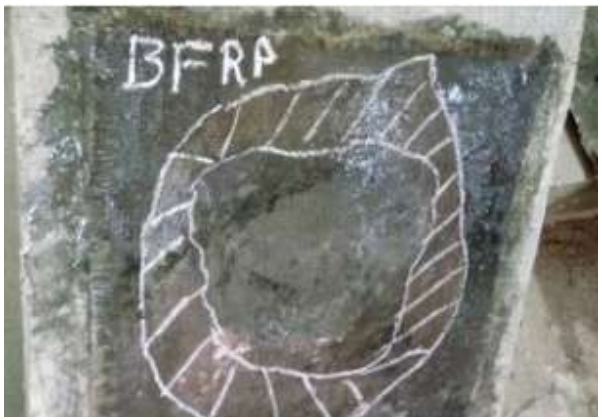

Fig 12: Failure pattern of BFRP wrapped rehabilitated slab

Bulging of the wrapping material at the bottom was observed in all type of fabrics except CFRP which debonded on number of blows due to its unidirectional nature. 
Though the energy absorption capacity remained somewhat same the area of bulging varied for different fabrics. Large bulged area was noticed in GFRP strengthened slabs. Next to GFRP was the BFRP, AFRP and least bulged fabric. But tearing of fabric was observed only in CFRP as it was unidirectional fabric. Thus this proves that Bidirectional fabric performance was better than unidirectional fabric under the Impact loading.

\section{CONCLUSION}

In the present study behavior of rehabilitated slabs under Impact loading was studied.10 slabs were cast, out of which 2 slabs were taken as control slabs and 2 slabs each were rehabilitated with CFRP, GFRP, BFRP and AFRP respectively. These slabs were subjected to Impact loading with a free fall height of $1 \mathrm{~m}$ and weight of drop hammer being $10.2 \mathrm{~kg}$. Based on the experimental study following conclusions are drawn.

- The rehabilitated slabs wrapped with CFRP, GFRP, BFRP and AFRP showed considerable increase in the Impact resistance compared to the control slabs by $46.75 \%, 26.74 \%, 60.09 \%$, and $73.44 \%$ respectively.

- The performance of Bidirectional fabric was found to be better since tearing was observed in unidirectional fabric.

- $\quad$ Out of CFRP, GFRP, BFRP and AFRP, bidirectional GFRP which is having less Tensile strength compared to other fabrics showed least increase in Impact resistance of about $26.74 \%$ compared to control slabs.

- $\quad$ Slabs wrapped with bi directional AFRP fabric having high Tensile Strength showed the maximum increase in Impact resistance and Energy absorption capacity of about $73.44 \%$ compared to control slabs. The fabric neither peeled nor teared off. Just bulging of the fabric was observed. The area of bulging was least of all the fabrics.

\section{Recommendations}

- AFRP bidirectional fabric is most economical and best suited material to strengthen or rehabilitate the damaged slabs because of its high tensile strength.

\section{REFERENCES}

[1] H. Min, J. -M. Yang, D. -Y. Yoo \& Y. -S. Yoon, "Flexural and Punching Performances of FRP and Fiber Reinforced Concrete on Impact Loading", ICE 2010 - The 5th International Conference on FRP Composites in Civil Engineering September 27-29, 2010, Beijing, China

[2] Guney Ozcebe, Ugur ersoy, Tugrul Tankut, Ugurhan Akyuzand Emrah Erduran, "Rehabilitation of Existing Reinforced concrete Structures using CFRP fabrics", 13th World Conference on Earthquake Engineering Vancouver, B.C., Canada August 1-6, 2004 Paper No. 1393

[3] Katrin Habel and D. Paul Gauvreau, "Impact Behavior Of Concrete Members Rehabilitated With
Uhpfrc Overlay", in 2nd International Symposium on Advances in Concrete through Science and Engineering 11-13 September 2006, Quebec City, Canada

[4] Mohamed Abdel-rohman \&Jihad Sawan, "Impact Effect Of RCC slabs Journal Of Structural Engineering ", 2 nd International Symposium on Advances in Concrete through Science and Engineering 11-13 September 2006, Quebec City, Canada

[5] Sudarsana Rao Hanchate, "Behavior Of High Performance Concrete Two Way Slabs In Impact For Fixed Edge Condition", inInternational Journal Of Emerging Trends In Engineering And Development, March 2015

[6] G.V.V SatyanarayanandDr.N.R.Dakshina Murthy "Studies On Response Of Two Way Blended Cement Concrete Slabs Under Impact Loads", in ICI JOURNAL, April-June 2015

[7] U. Ebead, H. Marzouk and L. M. Lye, "Strengthening of Two-Way Slabs Using FRP Materials: A Simplified Analysis Based on Response Surface Methodology", 2nd World Engineering Congress Sarawak, Malaysia,22-25 July 2002

[8] R.V.S.Ramakrishna,V Ravindra, "Experimental Investigation On Rehabilitation Of Reinforced Cement Concrete Interior Beam-Column Joints Using CFRP And GFRP Sheets", International Journal of science and Technology

[9] Deju Zhu; Barzin Mobasher, Subramaniam D. Rajan, Dynamic Tensile Testing of Kevlar 49 Fabrics", in journal of Materials in Civil Engineering March 2011.

[10] Norazean Shaaria, b, Aidah Jumahata, M. Khafiz M. Razifa," Impact Resistance Properties of Kevlar/Glass Fiber Hybrid Composite Laminates", in Jurnal Teknologi 2015.

[11] T Kiran, Sadath Ali Khan Zai, Srikant Reddy S, "Impact Test On Geopolymer Concrete Slab", in International Journal of Research in Engineering and Technology.

[12] Shubhalakshmi.B.S, Dr. H.N.Jagannatha Reddy, K.Arjun, "Flexural Strength of Two-Way RC Slabs Retrofitted with Basalt Fiber Reinforced Polymer", in International Journal Of Engineering Sciences \& Research Technology.2016

[13] N Jeevan, H N Jagannatha Reddy,"Comparative study on flexural strengthening of $R C$ beams using CFRP laminates by different techniques ", International conference on Advanced material technologies. (ICAMT)-2016

[14] M Amla, M neelamegam "Experimental study on flexural and impact on Ferro cement slabs." IOSR journal of mechanical and civil Engineering 2015.

[15] Tara Sen , H N Jagannatha Reddy , " Strengthening of $R C$ beams in flexure using Natural jute fiber textile reinforced composite system and its comparative study with CFRP and GFRP strengthening systems ",International journal of 
Sustainable Built Environment, vol -2, 2013 pp 4145.

[16] G L Oyekan “ Impact Resistance of Fiber reinforced laterized concrete" $26^{\text {th }}$ Conference on our world in concrete and structures,27-28, august 2001

[17] Handbook on Repair and Rehabilitation of RCC structures, published by Central Public works Department, Government of India,Nirman Bhavan. 